\title{
Dulcinea en la escritura de Juan José Arreola: recepción, intertexualidad y perspectiva de género
}

\author{
Paulo César Verdín Padilla ${ }^{1}$ y Perla Cristal Hermosillo Núñez ${ }^{2}$
}

Resumen. En este trabajo se utiliza la minificción “Teoría de Dulcinea”, escrita por Juan José Arreola, para analizar la recepción del personaje cervantino aludido en el título desde el discurso literario, el campo intertextual y la perspectiva de género. En el estudio se emplean las consideraciones de Wolfang Iser, teórico de la recepción y de las estudiosas de género Marcela Lagarde, Celia Amorós y Lucía Guerra. El abordaje metodológico se lleva a cabo a partir del método narratológico propuesto por Zavala. Las conclusiones del análisis apuntan hacia el personaje femenino en una faceta erótica y sensual, una Dulcinea diferente a las encontradas en el Quijote, la cual funciona como la propuesta del autor de la minificción. Asimismo, se enfatiza la fragmentación de la mujer y su subordinación frente al hombre, además de que cumple con el estereotipo de debilidad, sumisión, inferioridad e impureza y la figura masculina con fuerza, superioridad e intelectualidad.

Palabras clave: minificción; recepción; intertextualidad; perspectiva de género; Juan José Arreola.

\section{[en] Dulcinea in the writing of Juan José Arreola: reception, intertexuality and gender perspective}

\begin{abstract}
In this work the minifiction "Theory of Dulcinea", written by Juan José Arreola, is used to analyze the reception of the Cervantes character alluded to in the title, from the literary discourse, the intertextual field and the gender perspective. In the study, the considerations of Wolfang Iser, reception theorist and gender scholars Marcela Lagarde, Celia Amorós and Lucía Guerra are used. The methodological approach is carried out based on the narratological method proposed by Zavala. The conclusions of the analysis point to the female character in an erotic and sensual facet, a Dulcinea different from those found in Don Quixote, which works like the proposal of the author of the minifiction. Likewise, it emphasizes the fragmentation of women and their subordination to men, in addition to complying with the stereotype of weakness, submission, inferiority and impurity and the masculine figure with strength, superiority and intellectuality.
\end{abstract}

Keywords: minifiction; reception; intertextuality; gender perspective.

Cómo citar: Verdín Padilla, P. y Hermosillo Núñez, P.C. (2021) Dulcinea en la escritura de Juan José Arreola: recepción, intertexualidad y perspectiva de género, en Anales de Literatua Hispanoamericana 50, 329-334.

Limpias, pues, sus armas, hecho el morrión celada, puesto nombre a su rocín y confirmándose a sí mismo, se dio a entender que no le faltaba otra cosa sino buscar una dama

de quien enamorarse, porque el caballero andante sin amores era árbol sin hojas y sin fruto y cuerpo sin alma.

(Miguel de Cervantes)

Juan José Arreola nació en 1918 en Zapotlán el Grande, Jalisco, México hoy Ciudad Guzmán. Fue escritor, editor, formador de escritores mediante talleres literarios y actor. Algunas de sus obras son Varia invención

\footnotetext{
${ }^{1}$ Universidad de Guadalajara. México.

E-mail: pauloverdinp@gmail.com

${ }^{2}$ Universidad de Guadalajara. México.

E-mail: perlacritalorama@gmail.com
} 
(1949), Confabulario (1952), La feria (1963) y Palíndroma (1971) (Poot Herrera, 2009). Entre los géneros que abarcan su obra literaria se encuentra la minificción. Llamada minicuento, microrrelato, minitexto, microficción, textículo, relato enano, entre otros, es una forma de creación literaria que se ha difundido en la actualidad (Zavala, 2006). Se caracteriza por ser breve y lo común es que su extensión sea de un renglón a una página. Este tipo de textos contiene una referencia o temática conocida, de esta manera, el lector establece las relaciones intertextuales para comprenderlo. Otro rasgo sobresaliente del minicuento es que puede adoptar elementos de otras formas literarias, es decir, posee una estructura proteica (Rojo, 1997). Además, utiliza la sorpresa como un recurso recurrente para construir la narración (Zavala, 2006).

El texto elegido para realizar este trabajo es el microcuento titulado "Teoría de Dulcinea", incluido en la obra Bestiario (1972) en el apartado "Cantos de mal dolor". El objetivo de este trabajo es analizar la recepción del personaje cervantino, "Dulcinea" en este ejemplo de narrativa breve desde el campo intertextual y la perspectiva de género. Para realizar este propósito, se utilizará el método narratológico propuesto por Zavala (2007), el cual consiste en examinar los siguientes elementos de la obra narrativa: título, inicio, narrador, personajes, lenguaje, espacio, tiempo, género, intertextualidad y final. Se emplearán las consideraciones de Wolfang Iser, teórico de la recepción, perteneciente a la escuela de Constanza, y de las estudiosas de género Marcela Lagarde, Celia Amorós y Lucía Guerra.

En el título de esta minificción, una palabra importante es "teoría", definida como una hipótesis que intenta explicar un fenómeno (RAE, 2018). En este caso, hace referencia a las ideas expuestas en el texto para aludir a Dulcinea del Toboso, personaje principal femenino de Don Quijote de la Mancha de Miguel de Cervantes. El nombre propio Dulcinea presenta dos funciones en este minicuento: la primera es focalizar el personaje femenino y la segunda, señalar el intertexto. Por tanto, el análisis propuesto pretende dar cuenta de la lectura particular que Arreola hizo sobre este personaje cervantino a través de su minificción. El escritor jalisciense, al igual que el caballero andante, no pudo resistirse a la aventura de forjar a través de su escritura, su propia dama, la dueña de sus pensamientos. ${ }^{3}$

Con respecto a la focalización ${ }^{4}$, el autor coloca el centro de atención en el personaje femenino, el cual es percibido por el lector, quien potencializa la descripción de la protagonista con su conocimiento previo de la historia narrativa. Pimentel (2001) afirma que "El nombre propio se presenta como síntesis de una constelación de atributos, partes, relaciones y significaciones que informan al objeto nombrado" (32). Las significaciones previas que tiene el lector acerca de Dulcinea ${ }^{5}$ convergen en su imaginario cuando lee el título, el cual lo prepara para entender la propuesta de Arreola en torno al misterio que rodea a este personaje femenino en la trama de la minificción.

En cuanto al intertexto, el nombre propio Dulcinea, al referirse a un personaje literario, revela la obra de procedencia, Don Quijote de la Mancha. Esta indicación se lleva a cabo a manera de sinécdoque, la parte por el todo, pues su mención remite al lector a la obra completa. A partir de la economía del lenguaje con carácter descriptivo, Arreola alude a El Quijote sin ahondar en detalles, esto mediante la función de anclaje que consiste en identificar elementos específicos del relato, en este caso, el personaje femenino, mediante una interpretación guiada por el mensaje lingüístico (Barthes, 1986). De la misma forma, el inicio del texto alude a la obra clásica de manera más literal: En un lugar solitario cuyo nombre no viene al caso. ${ }^{6}$

Este microcuento se encuentra narrado en pasado. En esta temporalidad se distinguen dos historias. La principal es la que relata la vida del personaje masculino, quien se caracteriza por su propensión a la lectura de libros de caballería hasta su muerte; la secundaria atañe a lo que sucede en las páginas de la novela que lee el protagonista referido y funciona a manera de metanarración. ${ }^{7}$

\footnotetext{
${ }^{3}$ Arreola trata también al personaje femenino de Dulcinea en otra minificción titulada, "Dama de pensamientos", a propósito del epíteto que le da Don Quijote a la bella pastora Aldonza Lorenzo en el primer capítulo de la primera parte. El texto desarrolla la idealización de la mujer que recuerda el Dolce stil novo de los poetas italianos de la segunda mitad del siglo XIII.

4 "Ubicación de la mirada que observó los hechos, que puede no ser el narrador. El que focaliza es el enunciador del discurso [...], una de cuyas características consiste en poseer un saber total o parcial respecto a los hechos relatados, lo que proviene de la circunstancia de que él es un observador y la información que procura contiene su propio punto de vista (Beristáin, 2001: 356-357).

${ }^{5}$ Con respecto al nombre propio, "Dulcinea", una nota a pie de página de la Edición del IV Centernario de Don Quijote de la Mancha, elaborada por la Real Academia Española, explica que tanto el nombre de Dulce y Aldonza son nombres estrechamente relacionados entre sí en la actual provincia de Toledo. Incluso relaciona la terminación de "ea" de Dulcinea con otras figuras literarias, como el de Melibea, protagonista de La Celestina.

6 "En un lugar de la Mancha, de cuyo nombre no quiero acordarme" dice la primera línea del texto cervantino.

${ }^{7}$ Este fenómeno también es conocido como metadiégesis o narración de segundo grado y consiste en que "un personaje de la historia narrada, narra, a su vez, otra historia ocurrida sobre otra dimensión espacio-temporal con otros protagonistas o con los mismos" (Beristáin, 2001: 150).
} 
El elemento que permite distinguir entre una historia y otra son los personajes. El personaje masculino en el relato de Arreola se equipara con el caballero andante que participa en la novela para fusionar ambas historias mientras que el personaje femenino se encuentra fuera de la diégesis secundaria y es señalada como campesina y luego como pastora.

La trama se desarrolla en un espacio indefinido porque es calificado como un lugar solitario. El primer renglón recuerda el inicio de Don Quijote, por lo que podría presumirse que este lugar es la Mancha. Otro de los espacios importantes dentro del texto es el aposento, mencionado como una cueva. Este símbolo está relacionado con la feminidad, la matriz, la tierra y la represión, así como la muerte y el renacimiento (Morín, 2007). Además de estas características, se presentan los atributos de lo privado, lo cerrado y el espacio más íntimo de una casa. Es en la cueva donde aparece el personaje femenino, el cual posee cierto poder, pues el narrador la coloca en una posición ofensiva, puesto que sitia al anacoreta para lograr su rendición sexual. Una mujer de carne y hueso puso sitio al anacoreta en su cueva. La mujer es descrita desde el ámbito sensual cada vez que entra a este espacio: fuerte aroma de sudor y de lana.

En el mito de la caverna de Platón (1992) lo concreto está dentro de la gruta. Las sombras que ven los prisioneros son sinónimo de lo concreto, de lo sensitivo, de lo falso y de la mentira. Por eso no es casualidad que desde el principio del texto se describa a la mujer como "concreta" y se defina a partir de sus características físicas. En cambio, el prisionero que escapa de la caverna, según el filósofo griego, es el hombre que encuentra la razón. En este sentido, el personaje masculino está relacionado con las actividades intelectuales como la lectura y la reflexión, lo cual se refuerza con la distinción de anacoreta.

Por otro lado, el espacio público está relacionado con el personaje masculino. Es el espacio de la aventura y de la fantasía. Amorós (2001) indica: "son las actividades más valoradas las que configuran o constituyen el espacio público: es el espacio más valorado por ser el de reconocimiento, de lo que se ve, de aquello que está expuesto a la mirada pública, por definición" (24). En el texto, este lugar remite a ciertos capítulos de Don Quijote, como el I, el VIII, el XVII y el XXV de la primera parte y el capítulo final de la segunda parte, alusiones que potencializan en el lector las muchas aventuras del caballero de la triste figura.

El último espacio importante que se menciona es el cementerio, representado en el texto a manera de sinécdoque: la tumba. Es un lugar público y abierto, donde la mujer llora al hombre muerto. Resalta en el personaje femenino el lado emocional mediante las lágrimas y el lado físico, por el rostro.

En este minicuento se encuentra, en primera instancia, un narrador omnisciente total que conoce la historia, los sentimientos y el estado interior del personaje masculino. El narrador lo acompaña en su recorrido por las cientos de páginas que atestiguan las acciones de los personajes desarrolladas en la historia del libro que el hombre lee. Lo presenta como un protagonista inmerso en los mundos ficticios proporcionados por la lectura, a tal grado que prefiere vivir las aventuras descritas y fabricar su realidad alterna. La percepción interna que tiene el narrador acerca del personaje masculino muestra las sensaciones positivas que son producidas por las hazañas del caballero andante, protagonista de la novela que lee.

El narrador omnisciente se detiene en la vejez de este personaje. Esta etapa es importante porque es en ese momento cuando se encuentra con una mujer real, quien intenta seducirlo con su presencia. Él, elige nuevamente sumergirse en los mundos fantásticos y asumir el papel de caballero andante. ${ }^{8}$ De esta forma, el narrador presenta una hibridación o mimetización entre el personaje de la novela y el de la minificción. El narrador mantiene esa hibridación entre ambos al explicar la muerte del personaje masculino como si fuera la del caballero andante.

El narrador traslada de la omnisciencia total a la parcial cuando alude al personaje femenino. De éste presenta una perspectiva más superficial. Hace alusión al rechazo de la mujer real y a la preferencia del personaje masculino por la mujer plasmada en la ficción, cuyas virtudes y aspecto físico enmarcados en la fantasía satisfacen más al hombre. Al respecto, Lagarde y de los Ríos, indica que los hombres "pueden decidir y actuar sobre los hechos, sobre la vida y, de manera particular, sobre las mujeres" (324).

Cuando el personaje de la minificción de Arreola se encuentra con esa mujer real, el narrador resalta algunos aspectos sensoriales como su olor o su juventud. Al respecto, Guerra (2007) afirma que "lo masculino es sinónimo de la actividad y la conciencia [...] lo femenino, en cambio, denota el ámbito de lo pasivo e inconsciente, atribuyéndosele los referentes de la tierra, el agua y la luna" (31). Las alusiones a elementos internos de este personaje femenino son dos. La primera es la intención implícita de seducir al personaje masculino, la cual es deducida por el receptor después de una lectura atenta; la segunda se trata de

${ }^{8}$ Recuérdese que la locura de Alonso Quijano comienza cuando se enfrascó en los libros de caballería y “vino a dar en el más extraño pensamiento que jamás dio loco en el mundo... hacerse caballero andante" tal y como se señala en el primer capítulo de la obra. 
la tristeza que siente la mujer por la muerte del caballero, representada mediante las lágrimas que vierte sobre la tumba del protagonista.

El lenguaje utilizado en este microrrelato refuerza la presencia del intertexto, pues se encuentra compuesto de oraciones simples, caracterizadas por la presencia de descripciones y adjetivaciones que constituyen a los personajes y a las situaciones que los rodean. Las palabras utilizadas son una emulación del discurso encontrado en El Quijote pero con una mezcla de lenguaje contemporáneo que hace de este texto una obra original.

En la novela clásica referida como intertexto se identifican en la historia la presencia de diferentes facetas de Dulcinea. Fernando del Paso en su libro Viaje alrededor del Quijote señala diversas interpretaciones que se han realizado en torno a esta polémica protagonista: se le ha relacionado con abstracciones como libertad, sabiduría, gloria y fama. También se le ha vinculado como símbolo de la fe y bien universal. Incluso se le ha considerado como un desdoblamiento de don Quijote. "Para el lector común, Dulcinea no será jamás otra cosa que un personaje -o mejor dicho varios personajes- al que cada quién, cada lector, puede imaginar a su gusto" (2004: 216). En este sentido, Arreola propone una faceta más y diversa, una lectura distinta fuera de la obra cervantina, producto de las "indeterminaciones" que suscita el personaje. Siguiendo las ideas de Iser, Arreola llena un vacío de la novela, concretizando y actualizando a Dulcinea a través de su propio proceso de lectura del texto clásico. En efecto, Eagleton (1988), siguiendo las pautas del teórico alemán, señala al respecto que: "cada lector tiene libertad para actualizar la obra de diferentes maneras, y no existe una interpretación correcta y única que agoté el potencial semántico" (102). Así pues, tomando este derecho que el lector tiene, el autor jalisciense elabora su teoría acerca de tan polémico personaje.

Pero, independientemente de las interpretaciones que haga cada lector, incluyendo la propuesta de Arreola, la propia obra de Don Quijote genera una confusión en torno a este personaje porque parece desdoblarse en una multitud de Dulcineas, incluso opuestas, que conforman a la protagonista: "nunca se sabe cuál Dulcinea es la verdadera, si es que la hubo, y cuáles son las falsas, y si en todo caso era una labradora o una princesa, una virgen, una alucinación o un invento" (Del Paso, 2004: 205). La indeterminación del personaje se verifica desde su aparición en la obra, en el capítulo I de la primera parte, en donde el narrador señala como creencia, o a manera de rumor, la existencia de la labradora a la que bautizó con el nombre de Dulcinea, dio un particular epíteto y asoció a una toponimia específica:

Y fue, a lo que se cree, que en un lugar cerca del suyo había una moza labradora de muy buen parecer, de quien él un tiempo anduvo enamorado, aunque según se entiende, ella jamás lo supo ni le dio cata de ello. Llamábase Aldonza Lorenzo, y a ésta le pareció ser bien darle título de señora de sus pensamientos; y, buscándole nombre que no desdijese mucho del suyo y que tirase y se encaminase al de princesa y gran señora, vino a llamarla "Dulcinea del Toboso" porque era natural del Toboso (2004: 33).

En la obra se identifican distintos personajes femeninos relacionados con Dulcinea desde el punto de vista de don Quijote: él es quien la ve bella o la percibe encantada. La principal es la labradora Aldonza Lorenzo, cuya belleza es resaltada desde el inicio de la novela. Le sigue una opuesta, Dulcinea encantada, quien se caracteriza por ser una labradora fea y maloliente. En la cueva de Montesinos, el caballero andante reconoce por su ropa a otra Dulcinea, a la que nunca le vio el rostro. También se encuentra la Dulcinea imaginada, pues en algún momento de la historia don Quijote acepta que fue un invento suyo porque era obligatorio que un caballero andante tuviera una mujer idealizada a quien amar. Incluso, se encuentra Dulcinea hombruna, representada por un actor que se disfraza para jugarle una broma a Don Quijote. Otra Dulcinea, no menos importante que las demás, es la muerta, ya que Cervantes incluye su epitafio al final de la primera parte escrita en 1605. Hay muchas otras Dulcineas que el lector puede identificar en la lectura de esta obra, pues ésta aparece a modo de pastilla efervescente con el aparejado potencial de expandirse en el pensamiento del lector.

Ante este panorama, la novela de don Quijote se revela como un estímulo que incita al lector a resolver el misterio de Dulcinea. Arreola acepta el reto que ofrece el texto y expone su propia interpretación del personaje en un ejercicio de imaginación. Al respecto, señala Iser lo siguiente:

El texto literario activa nuestras propias facultades, capacitándonos para recrear el mundo que presenta. El producto de esta actividad creativa es lo que podríamos llamar la dimensión virtual del texto, la que le otorga realidad. Esta dimensión virtual no es el texto mismo, ni tampoco es la imaginación del lector: es la unión entre el texto y la imaginación (1987: 37). 
Si bien esta dimensión virtual está presente en todas las obras literarias, es en la minificción donde cobra mayor notoriedad. El autor pone a disposición del lector una pequeña cantidad de elementos esenciales que detonarán la historia en la mente lectora. Así, la historia abandona al texto y sólo se devela a través de un ejercicio de imaginación. La única condición necesaria para que suceda es que autor y lector deben compartir los mismos códigos. En este caso, es indispensable el conocimiento del intertexto que da origen a la minificción: El ingenioso hidalgo Don Quijote de la Mancha.

Ahora bien, la minificción en análisis parece caer en una contradicción. El título advierte de manera inicial que la mirada estará puesta en el personaje femenino, pero en el desarrollo de la historia la expectativa no se cumple por completo y el personaje más focalizado por el narrador es en realidad el personaje varón y su conflicto: evasión de la mujer y su preferencia por la fantasía. En este sentido, es necesario analizar qué papel juega la imagen femenina en la diégesis.

La primera referencia a la mujer se encuentra en las descripciones de la historia secundaria, la perteneciente a la novela que lee el personaje masculino. Ahí existen diversos adjetivos para nombrar a los personajes femeninos: vagos fantasmas femeninos, hechos de virtudes y faldas superpuestas, que aguardan al héroe. La mujer es vista como lo etéreo e inconstante, cuya virtud reside en ser capaz de esperar al caballero que se encuentra en batalla. Desde esta perspectiva, Guerra (2007) señala que las "oposiciones binarias entre lo activo masculino y lo pasivo femenino se reiteran en otro binarismo que asigna al hombre la escritura, la historia y el arte, en contraposición a la naturaleza asociada con la mujer" (45). En cambio, el hombre es representado como un aventurero que sortea diferentes obstáculos: se echó en pos a través de páginas y páginas, de un pomposo engendro de fantasía. Caminó muchas leguas, alanceó corderos y molinos, desbarbó unas cuantas encinas y dio tres o cuatro zapatetas en el aire. Las características que definen al hombre son su fuerza física, su capacidad de imaginar y la valentía para desafiar diferentes circunstancias.

En la historia principal se alude a un personaje femenino real, que existe fuera de la historia leída. Es concebido como una mujer seductora y salvaje que tiene como objetivo acorralar al personaje masculino para que cumpla sus deseos. Una mujer de carne y hueso puso sitio al anacoreta en su cueva. Con cualquier pretexto entraba al aposento y lo invadía con un fuerte aroma de sudor y de lana, de joven mujer campesina recalentada por el sol. La mujer es animalizada mediante la descripción física que se hace de ella: su juventud e instintos sexuales, éstos últimos reforzados con una sistemática del calor dentro del discurso: sudorosa y caliente por el sol. Al respecto, Lagarde (2005) indica que "las mujeres, a diferencia de los hombres, son su cuerpo" (200). En este microcuento, el cuerpo de la mujer está relacionado directamente con lo sexual, a través de connotaciones eróticas. Desde esta perspectiva, percibe el mundo mediante su cuerpo. $\mathrm{Su}$ vida se desarrolla en torno a qué se diga de él y cómo lo perciba y acepte el hombre porque es para los otros.

El personaje masculino no sucumbe a las insinuaciones femeninas por preferir el ejercicio mental a través de la imaginación que le proporciona la lectura, con lo cual se alude a su superioridad intelectual. Al respecto, Guerra (2007) señala que en el simbolismo "creado por la imaginación androcéntrica [...] subyace una dicotomía básica que asocia a la mujer con la naturaleza, mientras que al hombre se lo liga a la cultura" (Guerra, 2007: 31). De esta óptica, la mujer no se encuentra a la altura del caballero, tal vez por esa razón la rechaza.

La minificción "Teoría de Dulcinea” es un ejercicio de síntesis de la obra Don Quijote de la Mancha. El inicio es una paráfrasis hasta que el personaje muere. Arreola escribe un final diferente y aporta la inclusión del personaje femenino en una faceta erótica y sensual gracias a los elementos de indeterminación y vacíos que aporta la obra clásica de referencia. Al final, la mujer se encuentra subordinada al hombre de cuatro formas: por oficio; una pastora ante un caballero, por posición física; la mujer se encuentra ante la tumba, rindiéndole culto o admiración al hombre, por virtudes; el personaje femenino llora por la muerte del hombre, éste murió después de numerosas aventuras por el mundo, y por edad; el personaje masculino es viejo y el femenino es joven, lo que otorga al hombre una posición de sabiduría y experiencia, mientras que la juventud de la mujer se relaciona con la belleza y la sensualidad.

Además, se presenta la fragmentación de la mujer al señalar el rostro como única parte del cuerpo donde debe posarse la mirada del lector: un rostro polvoriento de pastora se lavó con lágrimas verdaderas, y tuvo un destello inútil ante la tumba del caballero demente. La descripción de ese rostro está relacionada con la suciedad y las lágrimas lo limpian para ser purificado. Este destello está relacionado con la belleza que en la resolución de la historia fue inútil. Incluso después de ese ritual de purificación, la pastora no es digna del caballero. La mujer fracasa, desde el punto de vista patriarcal, en su propósito de seducir al hombre a través de su juventud y belleza.

La figura femenina cumple con el estereotipo de debilidad, sumisión, inferioridad e impureza y la figura masculina con fuerza, superioridad e intelectualidad. Desde este punto de vista "las actividades femeninas, 
son las menos valoradas socialmente, fuere cual fuere su contenido, porque éste puede variar, son las que no se ven ni son objeto de apreciación pública" (Amorós, 2001: 25). Finalmente, hay que advertir que la interpretación que se ofrece aquí está sometida, como menciona otro pensador de la escuela de Constanza, Jauss, a un "horizonte histórico" y por tanto, relacionada a un lector también histórico (Eagleton, 1988: 105). Sólo resta decir, pues, que Arreola plasmó al personaje Dulcinea como lo hizo Don Quijote "píntola en mi imaginación como la deseo".

\section{Referencias bibliográficas}

Amorós, Celia (2001). Feminismo. Igualdad y diferencia. México: Universidad Nacional Autónoma de México.

Arreola, Juan José (1972), "Teoría de Dulcinea”, en Bestiario. México: Joaquín Mortiz.

Barthes, Roland (1986), "Retórica de la imagen”, en Lo Obvio y lo Obtuso. Barcelona: Paidós, págs.29-47.

Beristáin, Helena (2001). Diccionario de Retórica y Poética. México: Porrúa.

Cervantes, Miguel de (2004). Don Quijote de la Mancha. México: Real Academia Española.

Del Paso, Fernando (2004). Viaje alrededor del Quijote. México: Fondo de Cultura Económica.

Eagleton, Terry (1988). Una introducción a la teoría literaria. México: Fondo de Cultura Económica.

Guerra, Lucía (2007). Mujer y escritura. Fundamentos teóricos de la crítica feminista. México: Universidad Nacional Autónoma de México.

Iser, Wolfgang (1987). El acto de leer. Madrid: Taurus.

Lagarde y de los Ríos, Marcela (2005). Los cautiverios de las mujeres: madresposas, monjas, putas, presas y locas. México: Universidad Autónoma de México.

Morín, Edgar (2007). El hombre y la muerte. Barcelona: Kairós.

Pimentel, Luz Aurora (2001). El espacio en la ficción. México: Siglo XXI.

Platón (1992). República, Libro VII. Madrid: Gredos.

Poot Herrera, Sara (2009). Un giro en espiral. El proyecto literario de Juan José Arreola y otros ensayos sobre su obra. México: Universidad Autónoma de México.

Rojo, Violeta (1997). Breve manual para reconocer minicuentos. México: Universidad Autónoma Metropolitana.

Zavala Alvarado, Lauro (2007). Manual de análisis narrativo. Literario, cinematografía, intertextual. México: Trillas.

Zavala, Lauro (2006). La minificción bajo el microscopio. México: Universidad Nacional Autónoma de México. 